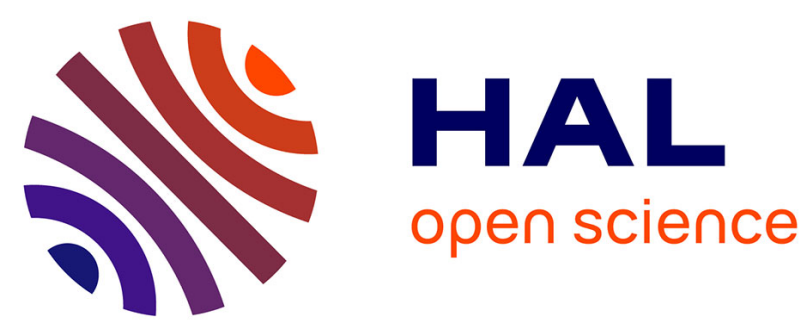

\title{
Expression of auxin-binding protein1 during plum fruit ontogeny supports the potential role of auxin in initiating and enhancing climacteric ripening
}

Islam El-Sharkawy, Sherif Sherif, Abdullah Mahboob, Kamal Abubaker, Mondher Bouzayen, Subramanian Jayasankar

\section{To cite this version:}

Islam El-Sharkawy, Sherif Sherif, Abdullah Mahboob, Kamal Abubaker, Mondher Bouzayen, et al.. Expression of auxin-binding protein1 during plum fruit ontogeny supports the potential role of auxin in initiating and enhancing climacteric ripening. Plant Cell Reports, 2012, vol. 31 (10), pp. 1911-1921. 10.1007/s00299-012-1304-2 . hal-00979256

\section{HAL Id: hal-00979256 https://hal.science/hal-00979256}

Submitted on 15 Apr 2014

HAL is a multi-disciplinary open access archive for the deposit and dissemination of scientific research documents, whether they are published or not. The documents may come from teaching and research institutions in France or abroad, or from public or private research centers.
L'archive ouverte pluridisciplinaire HAL, est destinée au dépôt et à la diffusion de documents scientifiques de niveau recherche, publiés ou non, émanant des établissements d'enseignement et de recherche français ou étrangers, des laboratoires publics ou privés. 


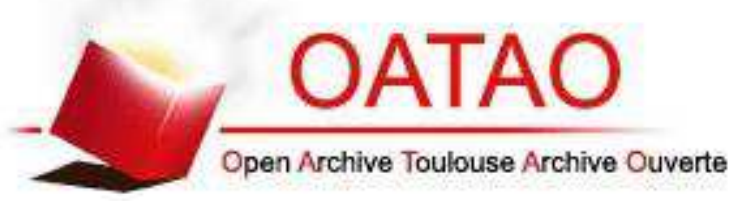

Open Archive Toulouse Archive Ouverte (OATAO)

OATAO is an open access repository that collects the work of Toulouse researchers and makes it freely available over the web where possible.

This is an author-deposited version published in: http://oatao.univ-toulouse.fr/ Eprints ID: 11379

Identification number: DOI : 10.1007/s00299-012-1304-2

Official URL: http://dx.doi.org/10.1007/s00299-012-1304-2

\section{To cite this version:}

El-Sharkawy, Islam and Sherif, Sherif and Mahboob, Abdullah and Abubaker, Kamal and Bouzayen, Mondher and Jayasankar, Subramanian Expression of auxin-binding protein1 during plum fruit ontogeny supports the potential role of auxin in initiating and enhancing climacteric ripening. (2012) Plant Cell Reports, vol. 31 ( $\mathrm{n}^{\circ}$ 10). pp. 1911-1921. ISSN 0721-7714

Any correspondence concerning this service should be sent to the repository administrator: staff-oatao@inp-toulouse.fr 


\title{
Expression of auxin-binding protein1 during plum fruit ontogeny supports the potential role of auxin in initiating and enhancing climacteric ripening
}

\author{
I. El-Sharkawy $\cdot$ S. Sherif • A. Mahboob • \\ K. Abubaker $\cdot$ M. Bouzayen $\cdot$ S. Jayasankar
}

\begin{abstract}
Auxin-binding protein1 (ABP1) is an active element involved in auxin signaling and plays critical roles in auxin-mediated plant development. Here, we report the isolation and characterization of a putative sequence from Prunus salicina L., designated PslABP1. The expected protein exhibits a similar molecular structure to that of well-characterized maize-ABP1; however, PslABP1 displays more sequence polarity in the active-binding site due to substitution of some crucial amino-acid residues predicted to be involved in auxin-binding. Further, PslABP1 expression was assessed throughout fruit ontogeny to determine its role in fruit development. Comparing the expression data with the physiological aspects that characterize fruit-development stages indicates that PslABPI up-regulation is usually associated with the signature events that are triggered in an auxin-dependent manner such as floral induction, fruit initiation, embryogenesis, and
\end{abstract}

Communicated by P. Kumar.

I. El-Sharkawy $\cdot$ S. Sherif $\cdot$ K. Abubaker · S. Jayasankar $(\bowtie)$ Department of Plant Agriculture, University of Guelph, 4890 Victoria Av. N, P.O. Box 7000, Vineland Station, ON LOR 2E0, Canada

e-mail: jsubrama@uoguelph.ca

I. El-Sharkawy $\cdot$ S. Sherif

Faculty of Agriculture, Damanhour University,

Damanhour, Egypt

A. Mahboob

Department of Biological Sciences, Brock University,

500 Glenridge Av., St Catharines, ON L2S 3A1, Canada

M. Bouzayen

UMR 990 INRA/INPT-ENSAT "Génomique et Biotechnologie

des Fruits", Av. de l'Agrobiopole, BP 32607,

31326 Castanet-Tolosan Cedex, France cell division and elongation. However, the diversity in $P s l A B P 1$ expression profile during the ripening process of early and late plum cultivars seems to be due to the variability of endogenous auxin levels among the two cultivars, which consequently can change the levels of autocatalytic ethylene available for the fruit to co-ordinate ripening. The effect of auxin on stimulating ethylene production and in regulating $P s l A B P 1$ was investigated. Our data suggest that auxin is involved in the transition of the mature green fruit into the ripening phase and in enhancing the ripening process in both auxin- and ethylene-dependent manners thereafter.

Keywords Auxin - Fruit development and ripening . Protein structure $\cdot$ Subcellular localization

\author{
Abbreviations \\ ABP1 Auxin-binding protein1 \\ DAB Days after bloom \\ 'EG' 'Early Golden' \\ 'SH' 'Shiro' \\ S1-4 Stage 1-4
}

\section{Introduction}

The phytohormone auxin controls almost every aspect of plant growth and development processes. At cellular level, auxin regulates cell division, expansion and differentiation (Friml 2003). Some short-term effects may reflect direct auxin impact on cell membrane proteins; however, most other responses appear to include changes in gene expression (Lüthen et al. 1999). At the whole plant level, auxin controls essential processes such as apical 
dominance, lateral root formation, tropic responses, initiation and differentiation of vascular tissues, embryogenesis, and fruit development (Teale et al. 2006; Quint and Gray 2006). The involvement of auxin in a diverse array of critical physiological functions may well be mediated by an equally diverse array of receptors and an intricate network of signaling cascades. Identification of auxin receptors involved in signaling systems is a particularly significant step towards understanding the molecular basis of auxin action. Through determining the auxin-binding activity, three types of auxin receptors have been identified so far: auxin-binding protein 1 (ABP1) that is involved in auxin signaling within the plasma membrane (Shimomura et al. 1999; Leblanc et al. 1999) but with an incompletely known physiological role (Davies 2004), members of germin-like protein (GLP) superfamily that exhibits low auxin-binding affinity (Ohmiya et al. 1993; Yin et al. 2009) and the transport inhibitor response proteins (TIR1-like) that have a role as an auxin receptor for mediating transcriptional regulation via rapid Aux/IAA protein degradation (Kepinski and Leyser 2005; Dharmasiri et al. 2005). Apparently, the potential receptors ABP1 and some GLPs are associated with the regulation of rapid cytosol-based signalling mechanisms; however, TIR1-like proteins are associated with the proteasome-regulated proteolysis of proteins critical for rapid gene regulation within the nucleus (Scherer 2011).

A lot of research has been focused on ABP1. ABP1 is ubiquitous in green plants but its physiological role is unclear. It was first identified in crude membrane preparations of etiolated coleoptiles (Hertel et al. 1972). Later, its capacity to bind auxin was clearly determined (Löbler and Klämbt 1985). In general, ABP1s exhibit considerable conservation in the sequence of mature protein across a broad range of plant species. The crystal structure indicates that ABP1 belongs to the cupin protein superfamily (Woo et al. 2002). Usually, the members of cupin superfamily hold a manganese-binding histidine cluster (Dunwell et al. 2000); however, in ABP1, the predominant metal ion was determined to be zinc (Woo et al. 2002). Following the initial identification of maize-ABP1, other orthologs have been characterized in a range of plants and its functions have been determined using different approaches. All these studies demonstrated that ABP1 binds auxin at levels corresponding to physiological concentrations within the plasma membrane (Shimomura et al. 1999; Kim et al. 2000). Further, characterization of ABP1 through overexpression or functional inactivation in plants and cell cultures illustrated its essentiality on the cell cycle, embryo development, root growth and floral induction (Jones et al. 1998; Bauly et al. 2000; Hou and Huang 2005; David et al. 2007; Tromas et al. 2009; Chen et al. 2011).

Fruits can be classified as climacteric or non-climacteric depending on the presence or absence of postharvest, ripening-associated rise in ethylene evolution and respiration (Biale and Young 1981). Japanese plums (Prunus salicina L.) are climacteric fruits characterized by a large diversity for the date and rate of ripening. However, the availability and characterization of mutant plants in some species like tomato, whose fruits are unable to ripen even when treated with exogenous ethylene has helped to identify quite a few of the developmental factors that act upstream of ethylene and control the ripening process (Giovannoni 2004). The role of these factors is as important as the role played by ethylene. Previous studies suggested that auxin can be involved in the fruit ripening (Miller et al. 1987; El-Sharkawy et al. 2008, 2009) as exogenous applications of the hormone can stimulate the ripening process (Ohmiya 2000; Bregoli et al. 2007; Trainotti et al. 2007; El-Sharkawy et al. 2010). Thus, it seems that auxin can be also a part of the mechanisms that control the capacity of the fruit to ripen.

In this study, we report the isolation and characterization of a putative ABP1 in plum. Comparing with the crystallized maize-ABP1, mature PslABP1 protein exhibit, generally, similar molecular structure; however, the plum protein is predicted to be more hydrophobic due to substitution of some critical amino-acid residues involved in the auxin-binding activity. Moreover, PslABPl expression profile during fruit ontogeny was investigated to determine the contribution of auxin in fruit development. In addition, its expression was quantified during ripening of two plum cultivars with different ripening rates. The aim was to determine whether there are dissimilarities that could account for the diversity in ripening behaviour. The ability of auxin in stimulating the ripening process was also investigated.

\section{Materials and methods}

\section{Plant material and postharvest treatments}

Fruits from two Japanese plum cultivars 'Early Golden' ('EG') and 'Shiro' ('SH') were harvested and treated as described previously (El-Sharkawy et al. 2007). Other tissues such as flowers and early stages of fruit development were collected from 'SH' cultivar. To evaluate IAA-induced ethylene production in plum fruit, mature 'SH' fruits were harvested and treated with either the auxin-IAA or auxin transport inhibitor-TIBA as indicated previously (El-Sharkawy et al. 2010); non-treated fruits were used as control. All plant materials were frozen in liquid nitrogen and stored at $-80{ }^{\circ} \mathrm{C}$ for RNA analysis. Total RNA was extracted using the methods described by Meisel et al. (2005). All RNA extracts were treated with DNase I (Promega, Madison, WI, USA) then 
cleaned up with RNeasy mini kit (Qiagen, Mississauga, ON, Canada).

Isolation and in silico analysis of $P S I A B P 1$ sequence

Based on the sequence similarity among various $A B P 1 s$, a pair of degenerate primers, ABP1-F and ABP1-R (primers 1 and 2 in Table 1), were designed from conserved regions to amplify $A B P 1$ orthologs from $P$. salicina. The isolated fragment was cloned in pGEM-T easy vector (Promega), sequenced and compared with database sequences using the BLAST program (Altschul et al. 1997). Extension of the partial cDNA clone was carried out using the $3^{\prime}$ - and 5'-RACE kit (Invitrogen, Burlington, ON, Canada). Fulllength amplification of cDNA sequence, designated PslABP1, was carried out using the Platinum Taq DNA Polymerase High Fidelity following the instructions provided by the manufacturer (Invitrogen). Alignment of PslABPl predicted protein sequence and the neighborjoining tree construction were performed as described previously (El-Sharkawy et al. 2008). Genomic DNA was extracted from plum immature leaves according to the DNeasy Plant Maxi Kit (Qiagen). Full-length amplification of genomic sequence, designated $g P s l A B P 1$, was carried out using Platinum Taq DNA Polymerase High Fidelity (Invitrogen).

Protoplast isolation and transient expression of PslABP1-GFP fusion protein

The coding sequence of PslABP1 was cloned as a C-terminal fusion in frame with the GFP into the pGreenII vector using Bam $\mathrm{HI}$ site (primers from 3 and 4 in Table 1) and expressed under the control of the $35 \mathrm{~S}$ promoter. Protoplasts used for transfection were obtained from suspension-cultured tobacco (N. tabacum) BY-2 cells. Protoplasts were transfected and analyzed for GFP fluorescence by confocal microscopy as described previously (El-Sharkawy

Table 1 The oligonucleotide primers used

\begin{tabular}{ll}
\hline Name & Oligonucleotide sequence \\
\hline 1- ABP1-F & 5'-ATCCACAGGCATTCNTGTGAAGAAG-3' \\
2- ABP1-R & 5'-GAACACTTTVACTGGTGGACGAG-3' \\
3- ABP1(FG) & 5'-CGCGCGGATCCATGGCAGGGCC \\
& TTCTCTT-3' \\
4- ABP1(RG) & 5'-CGCGCGGATCCCTAGCTCGTC \\
& CTTTGGCG-3' \\
5- RtABP1-F & 5'-CACGAGAAGTCCCCTGGA-3' \\
6- RtABP1-R & 5'-GGACCTGGTGAGCATCGT-3' \\
7- Ps-actin(F) & 5'-CTGGACCTTGCTGGTCGT-3' \\
8- Ps-actin(R) & 5'-ATTTCCCGCTCAGCAGTG-3' \\
\hline
\end{tabular}

et al. 2009). All transient expression assays were repeated at least three times.

Three-dimensional structure modeling

The molecular modeling of PslABP1 was carried out using SwissModel server. The crystal structure of Maize-ABP1 (PDB: 1LRH) (Woo et al. 2002) was used as a template to build the three-dimensional model of the PslABP1. MaizeABP1 has a sequence identity of $68 \%$ with the plum target protein. The model was achieved with an E-value of $1.76^{\mathrm{e}-56}$.

Real time quantitative RT-PCR

All RT-PCRs were performed as described previously (ElSharkawy et al. 2012). Primer Express (v3.0, Applied Biosystems, Carlsbad, CA, USA) was used to design genespecific primers (primers from 5 to 8 in Table 1). Three biological and three technical replicates for each reaction were analyzed on an ABI PRISM 7900HT Sequence Detection System (Applied Biosystems). Transcript abundance was quantified using standard curves for both target and reference genes, which were generated from serial dilutions of PCR products from corresponding cDNAs. Transcript abundance was normalized to the reference gene [PsAct (EF585293)] that shows high stability across the different treatments.

\section{Results and discussion}

Protein structure and organization

In the present work, a putative auxin-binding protein 1 $(P s l A B P 1)$ that is a member of cupins protein superfamily was identified. PslABPl cDNA sequence (JN176136) is $695 \mathrm{bp}$ in length with a predicted open reading frame encoding a protein of 191 amino acids. The 5'-, 3'-noncoding, and poly $\left(\mathrm{A}^{+}\right)$sequences were 36,80 , and $12 \mathrm{bp}$, respectively. Isolation of corresponding full-length genomic sequence (JN176137) resulted in a fragment of $1,887 \mathrm{bp}$ in length that comprises five exons interrupted by four introns, which is consistent with several ABP1 genes from different plant species (Fig. 1a). PslABPl predicted amino-acid sequence includes all the conserved structure elements that are important for the protein function (Fig. 1b) (Napier et al. 2002). It comprises a characteristic extracellular targeting peptide signal located at the $\mathrm{N}$ terminus, which supports an apoplastic or plasma-membrane localization. A signal peptide search (Nielsen et al. 1997) showed a cleavage prediction of the hydrophobic targeting peptide would occur after Ala-22. Excluding the 


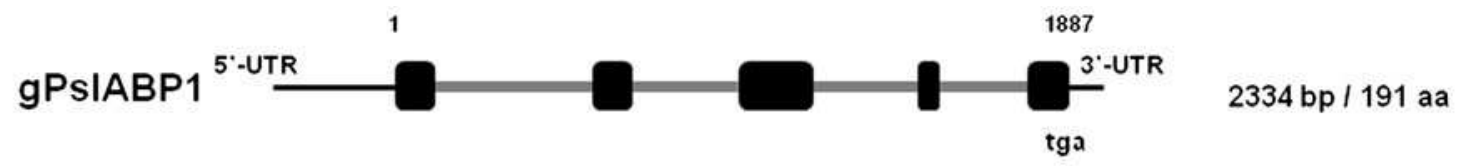

b
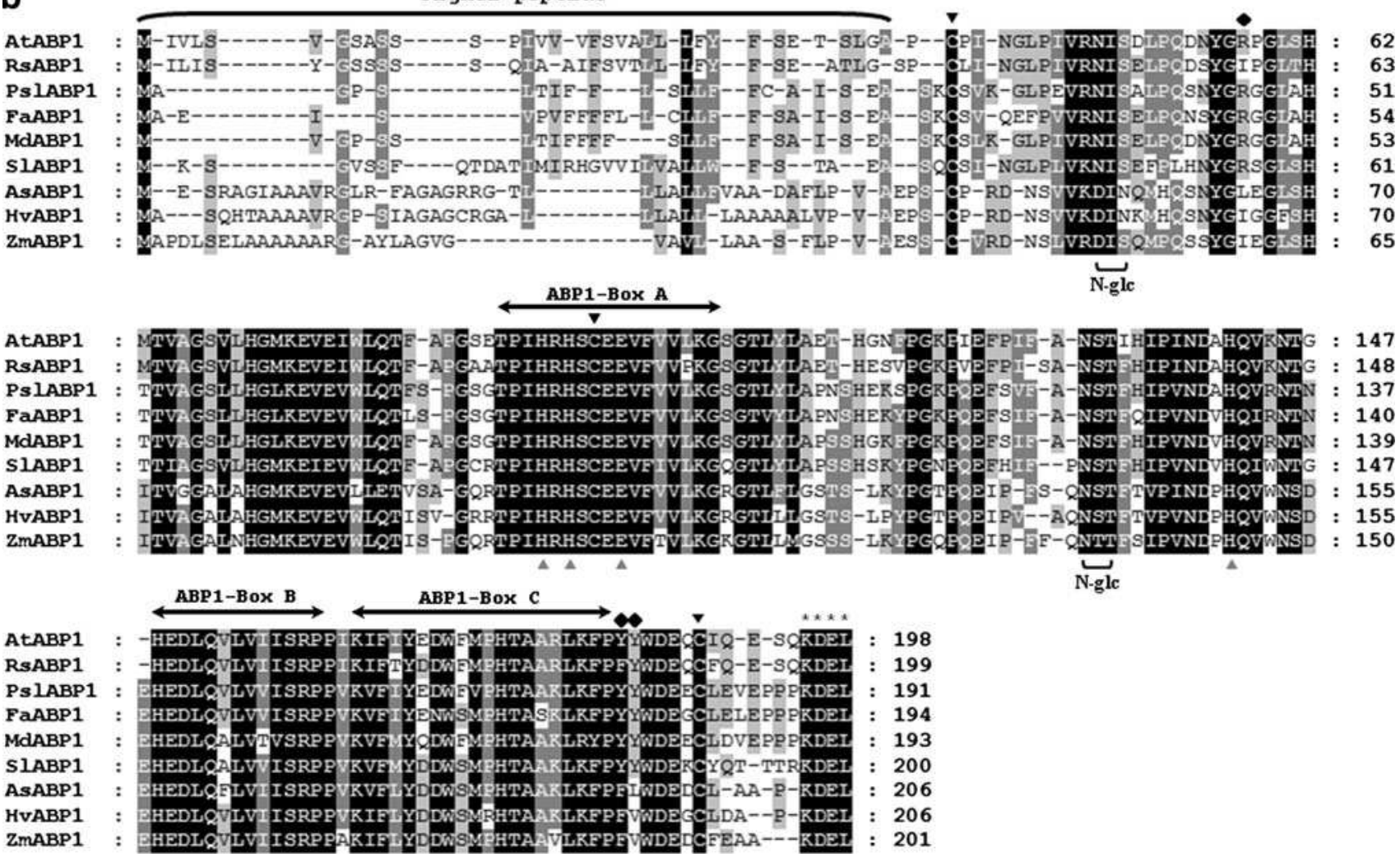

Fig. 1 Sequence analysis of plum PslABP1. a Genomic structure of PslABP1. The black boxes represent the exons, the grey lines the introns and black lines the untranslated regions (UTRs). b PslABP1 amino-acid sequence alignment with closely related sequences using ClustalX program. Conserved residues are shaded in black. Dark grey shading indicates similar residues in seven out of nine of the sequences and clear grey shading indicates similar residues in five out of nine of the sequences. Putative $\mathrm{N}$-terminal signal sequences are indicated by "Signal peptide". Boxes $A, B$ and $C$ correspond to the

N-terminal signal sequence that shows a considerable sequence divergence, PslABP1 mature protein shares sequence identity ranging from 63 to $87 \%$ with closely related homologues from different plant species. The mature protein, which is 169 amino-acids long contains the three domains, labelled as boxes A (known also as D16 box, metal-binding site and auxin-binding site), B and C that are highly conserved amongst all plant ABP1s. Box A contributes two of the three histidines (His-59, His-61, and His-109; numbers referred to PslABP1 mature protein) and the glutamic acid (Glu-65) residues involved in heavymetal ion-binding site (Anai et al. 1997), which was determined to be $\mathrm{Zn}^{2+}$ (Woo et al. 2002). Box A also includes a cysteine residue (Cys-63), which is preceded and followed by two other cysteines (Cys-3 and Cys-158, three highly conserved domains among all ABP1s (Napier et al. 2002). The conserved three cysteine residues are pointed with three black arrows. The three histidines and the glutamate amino-acid residues involved in $\mathrm{Zn}^{2+}$-binding are pointed with four gray arrow heads. The amino-acid residues that differ between monocots and dicots are indicated by three black diamonds. The two potential $N$-glycosylation sites of PslABP1 sequence are indicated by " $N$-glc". The ER retention motif (KDEL) is indicated with four asterisks

respectively). It was predicted that two of them form an internal disulfide bridge of the extracellular domain, which stabilizes the protein both in the presence or absence of bound auxin (Woo et al. 2002). The finding of a precisely localized disulfide bond within ABP1 typically indicates either an extracellular localization or a compartmented residence for the protein (Thornton 1981). Previous work provided proof for the presence of a disulfide bridge between the two cysteines located in the N-terminal and the central region of maize-ABP1 (Feckler et al. 2001). However, the mutation of the cysteine residue located at C-terminal region of tobacco-ABP1 altered the folding of the protein, its capacity to interact with auxin and its activity at the plasma membrane (David et al. 2001). In contrast, the presence of only one cysteine residue out of 
three in sunflower-ABP1 (Thomas et al. 2003) raises the question as to what extent the disulfide bridge is required for ABP1 function. Consistent with ABP1s from other plants (Napier 2001); two potential $\mathrm{N}$-glycosylation sites were identified in PslABP1 predicted protein. Some sequences possess three putative glycosylation sites such as the strawberry-ABP1 and there is evidence that all are functional (Lazarus and MacDonald 1996). In contrast, sunflower-ABP1 holds only one glycosylation site (Thomas et al. 2003). The majority of $N$-glycosylation genes are transmembrane proteins that function in the endoplasmic reticulum and Golgi apparatus, and play important roles in diverse biological processes such as protein folding, confirmation, stability and targeting (Varki 1993; Kukuruzinska and Lennon 1998). In addition, mature PslABP1 protein holds a typical C-terminal KDEL sequence, a signal known to be responsible for the retention of soluble protein to the lumen of the endoplasmic reticulum (Napier 1997). The ABP1/KDEL is essential for the stability of the protein and involved in the interaction with the plasma membrane but not necessary for the auxinbinding activity (David et al. 2001). The previous analysis typically points out proteins with a cytoplasmic localization compartment. Our results show that GFP distribution in the control was spread throughout the cytoplasm and nucleus; however, PslABP1-GFP fusion protein was totally excluded from the nucleus and exclusively targeted to the cytoplasm and plasma membrane (Fig. 2) where the $\mathrm{pH}$ is optimal for high-affinity auxin-binding (Jones and Herman 1993; Napier et al. 2002).

A phylogenetic tree, comprising $13 \mathrm{ABP} 1$ sequences from different species, was generated (Fig. 3). The dendrogram clearly divided ABP1s into two main classes, monocots and dicots. To further determine the amino-acid residues crucial for ABP1 classification, a molecular model of PslABP1 was built using the maize-ABP1 structure as a template. Comparing the PslABP1/1-NAA model complex with that of maize (Fig. 4a, b) revealed the presence of the hydrophobic platform necessary to pack the naphthalene ring of 1-NAA in both proteins (Woo et al. 2002). Thus, it is feasible to speculate that the affinity of PslABP1 to bind 1-NAA should be similar to that of maize-ABP1 protein. Further, comparison between plum- and maize-ABP1 protein structures indicated that the binding site in PslABP1, generally, displays more sequence polarity than its counterpart in maize. Of particular interest is the substitution of a Phe-149 in maize with a Tyr-152 in plum at a position adjacent to where IAA-imidazole group would be present. The consequence of this substitution is compounded by the attendance of an Arg-24 in plum in place of an Ile-22 in maize within a hydrogen-bonding distance of the Tyr-152. Analysis of mature ABP1s across a broad range of plant species revealed that these substitutions are conserved among all the dicots examined so far with the exception of Raphanus (Fig. 1b); however, co-crystallization of PslABP1/IAA complex model pointed out that such substitutions may have implications for auxin-binding activity, which can only be confirmed by experimental binding-assay. To investigate the effect of the increase in polarity on the active site, a molecule of IAA was placed in-lieu of the 1-NAA molecule with the carboxyl group fixed to the same position as that of the 1-NAA. Moreover, the other zinc ligands were also fixed to not allow a deviation within the coordination sphere of zinc. Minimization was carried out on the rest of the protein and IAA in the binding site (Fig. 4c, d). The resulting geometry shows a hydrogen bond of $2.76 \AA$ between IAA-Imidazole group and Tyr-152 hydroxyl oxygen of PslABP1 mature protein. Furthermore, Tyr-153 along with Arg-24 forms a hydrogen bonding network that can provide an anchor to IAAbinding (Fig. 4c). However, in case of maize-ABP1, the binding of IAA is not stabilized by any amino-acid interactions and only stabilized by the coordination to the zinc metal ion (Fig. 4d). Hydrophobic interactions, however, can be seen as a stabilizing force, especially, among the aromatic residues as pi-pi stacking interactions are possible. The previous characterization indicated that the isolated plum sequence is encoding a putative auxin binding protein1 that may be function as an auxin receptor. However, that can only be confirmed by experimental bindingassay or by performing genetic screens, which cannot be done easily in tree species.

\section{PslABP1 expression during fruit ontogeny}

The expression profile of PslABP1 was carried out in flowers and through different fruit-developmental phases to elucidate the physiological role of auxin in fruit development. Jones (1994) and Napier and Venis (1995) mentioned that $A B P 1$ transcripts could accumulate in the entire plant ubiquitously, suggesting that $A B P 1$ expression is not tissue specific.

PslABPl transcripts were initially low in flower buds, but increased strongly afterwards. The abundance of PslABP1 after fertilization $(\sim 7 \mathrm{DAB})$ represented the highest mRNA level among the whole experiment (Fig. 5; flower). The enlargement of ovaries that continues after fertilization is essentially due to auxin-induced cell expansion resulting in fruit-development initiation (Leblanc et al. 1997; Miller et al. 1987). It has been previously suggested that flowers are sites of auxin production in plants and auxin has been shown to influence the development of flower parts and fruit setting (Lang 1961). Thus, the previous results suggest the involvement of $P S I A B P 1$ in regulating auxin actions leading to fruit initiation events and perhaps embryo formation. Earlier genetic studies 


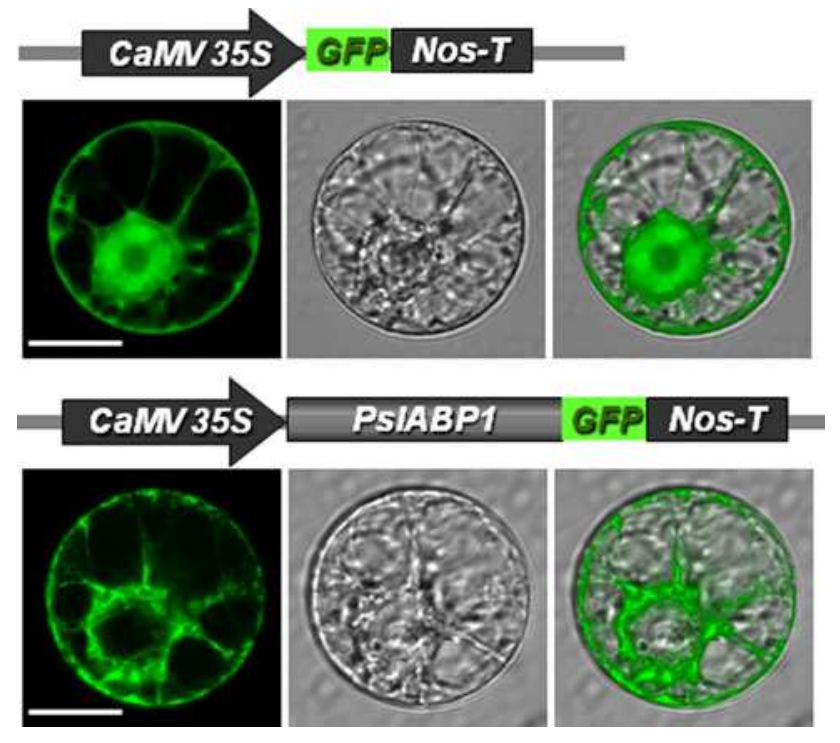

Fig. 2 Subcellular localization of PslABP1 protein fused to the GFP tag. Constructs consisting of either the control 35S::GFP or 35S::PslABP1-GFP were used transiently to transform $N$. tabacum protoplasts. The subcellular localizations of the GFP protein under the control of $35 \mathrm{~S}$ or the PslABP1-GFP fusion protein were analyzed using confocal laser scanning microscopy. Light micrographs (centre panel) and fluorescence (left panel) images are merged (right panel) to illustrate the different locations of the two proteins. The length of the bar corresponds to $10 \mu \mathrm{m}$

provided strong evidence regarding the role of ABP1 in mediating the regulatory pathway of auxin-induced cell division, elongation and embryogenesis (Jones 1994). Chen et al. (2001) demonstrated that the homozygous ABP1 knockout mutant is lethal due to defects during early embryogenesis. Tobacco- and sunflower- $A B P 1$ were most abundant in organs that respond to auxin stimulus, such as the developing flowers and new growth. These tissues are typical target for auxinic signals involved in the induction of various processes such as cell division, elongation and differentiation (Leblanc et al. 1997; Chen et al. 2011).

The stone fruit-development period could be divided into three different stages based on growth pattern (ElSharkawy et al. 2007). The first stage (S1, 22-37 DAB) illustrated by intense cell division, differentiation and rapid growth caused by elevated quantities of auxin (Miller et al. 1987). During this period, PslABPI transcripts gradually increased to a peak $(\sim 32 \mathrm{DAB})$ and declined thereafter (Fig. 5; S1). It seems that PslABP1 is required for regulating auxin signaling leading to the abundant cell division and expansion during early embryo morphogenesis characterizing this stage. PslABP1 transcripts continued to decrease reaching constant basal levels throughout S2 (Fig. 5; S2). During S2 period (42-52 DAB) there is hardly any visible increase in fruit size (no evidence of cell division or expansion), which coincided with a significant reduction in auxin content (Miller et al. 1987). However, the only fruit-development process throughout S2 is the lignification of the endocarp to form a solid stone. Thus, the accumulation profile of $P S I A B P 1$ along with the growth pattern of the fruit suggested a minor role for auxin within S2. During S3 (57-77 DAB), when the pulp (mesocarp) separates easily from the seed (endocarp + embryo), PslABPl significantly accumulated in both fruit tissues; however, its accumulation profile in the pulp was totally different than those in the seed (Fig. 5; S3). In the pulp,

Fig. 3 Phylogenetic relationships between $P$. salicina $\mathrm{ABP} 1$ and other sequences from $A$. thaliana (NP_192207), $R$. sativus (BAA25432), H. annuus (AAQ04680), F. ananassa (CAA62956), M. domestica (AAB47752), N. tabacum (CAA50259), S. lycopersicum (CAA09882), C. annuum (CAA88361), A. sativa (BAA25433), $H$. vulgare (BAK06211), Z. mays (CAA40061) and O. sativa (ABA98773) based on fulllength amino-acid sequence. Monocots and dicots correspond to the two different classes of $\mathrm{ABP} 1$ sequences

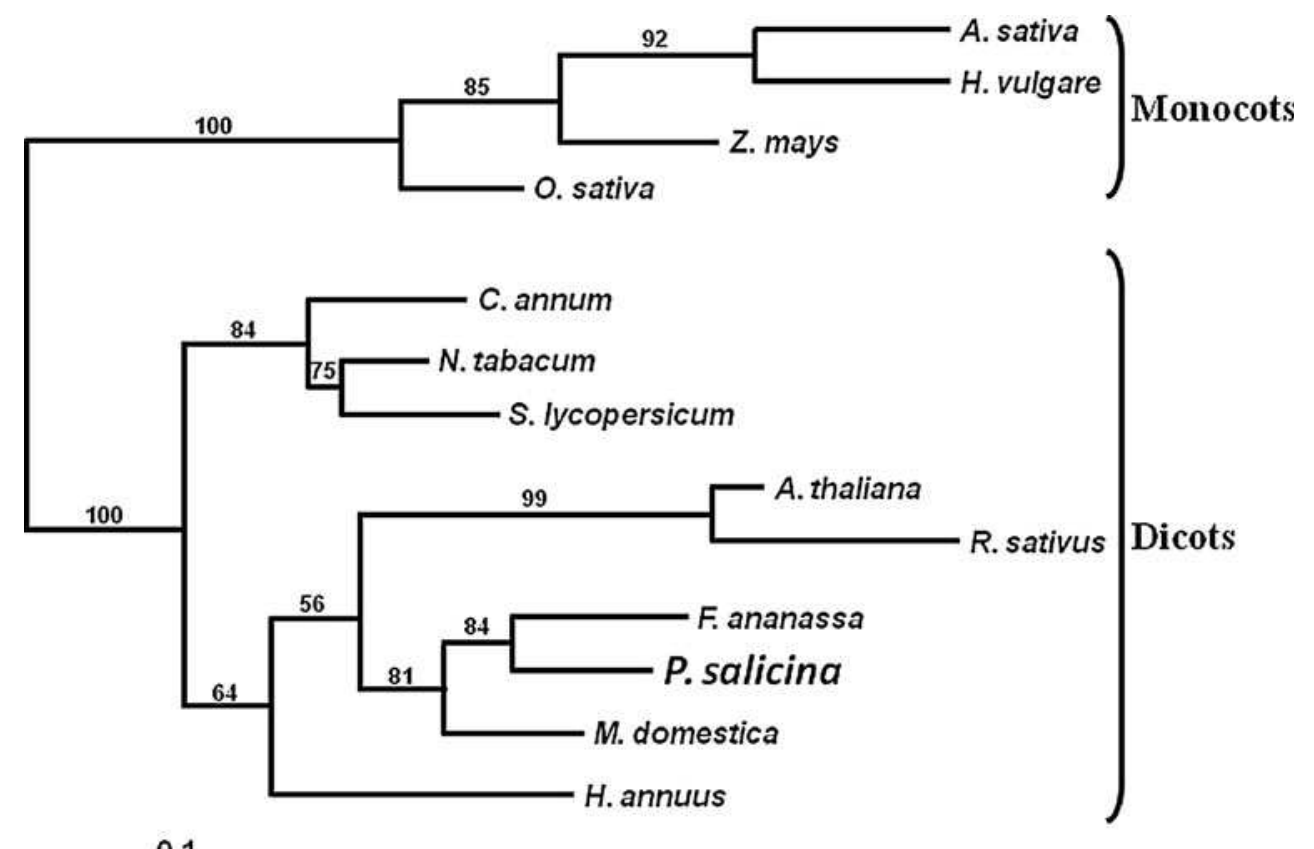

0.1 
Fig. 4 Molecular structure of plum- and maize-ABP1 auxin binding site in complex with 1-NAA (a and $\mathbf{b}$, respectively) and IAA (c and d, respectively). Active-binding site of plumABP1 has more polar aminoacid residues than that of maize allowing for a hydrogen bond network between the imidazole group of IAA, Tyr-152, Tyr-153, and Arg-24
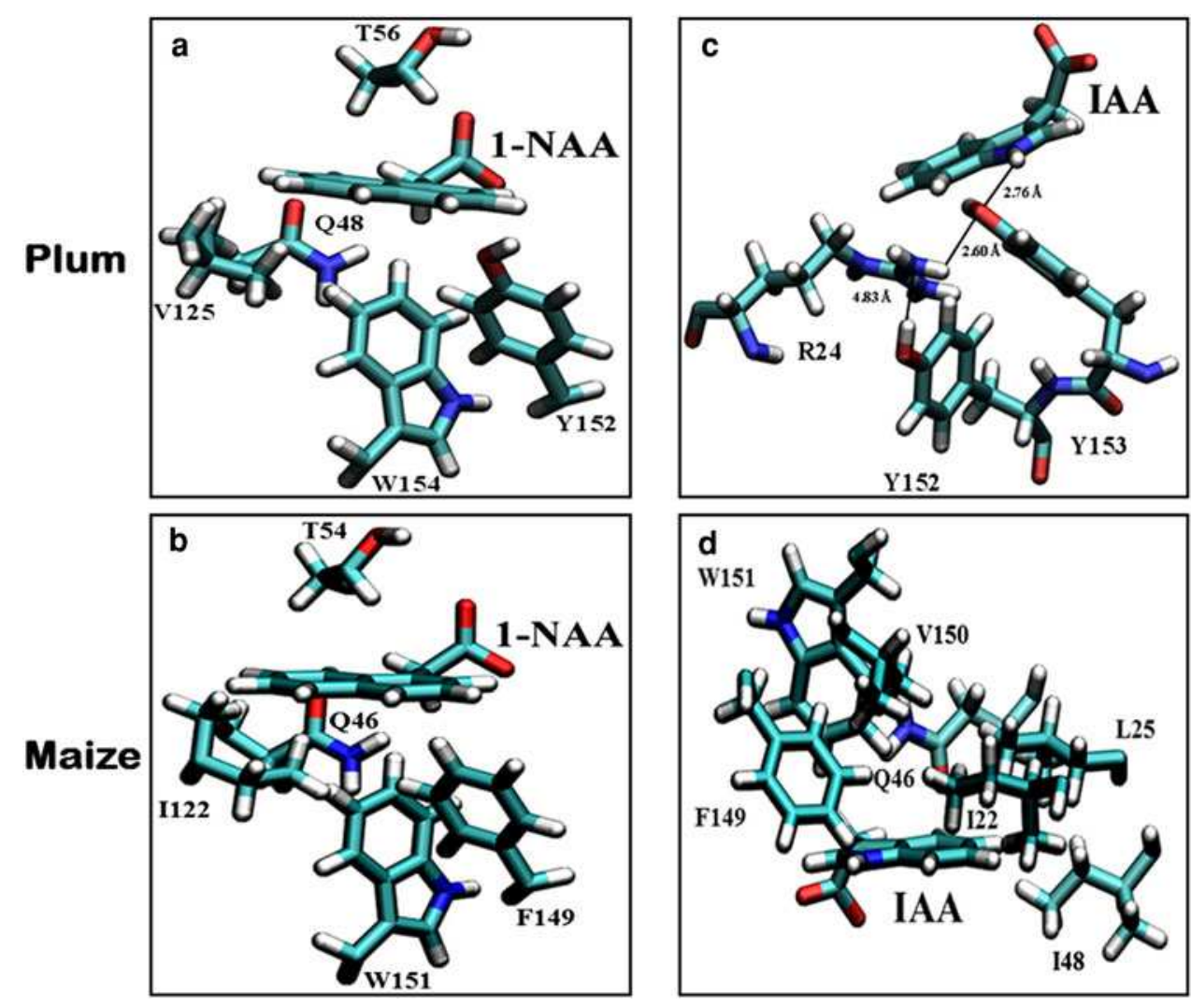

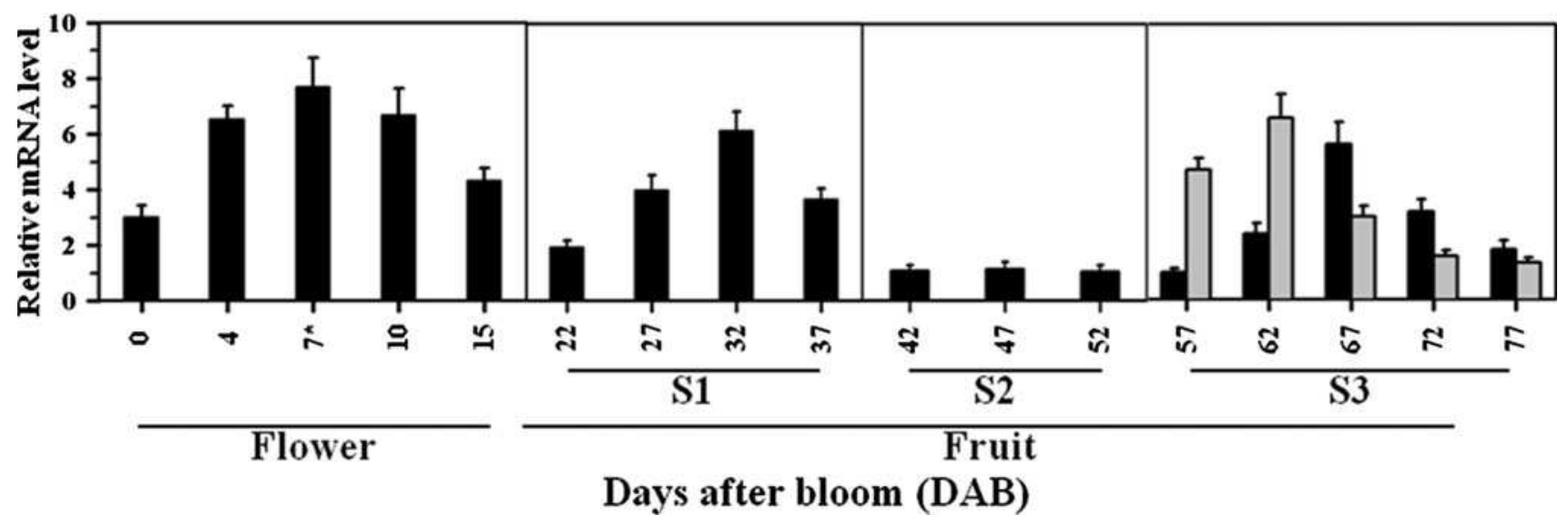

Fig. 5 Steady-state transcript levels of PslABP1 assessed by QRTPCR during 'EG' fruit ontogeny (the fertilized flowers stage is marked with an asterisk). During S1 and S2 phases the whole fruit was used for RNA analysis; however, through S3 stage the expression was determined in pulp (black bars) and in seeds (grey bars). The

PslABPl mRNA increased to a peak $\sim 67 \mathrm{DAB}$ and gradually decreased thereafter reaching a minimal level at the end of S3. However, in the seed, PslABP1 levels were high at the beginning of S3 ( 57-62 DAB) and declined subsequently to reach a basal level by the end of the stage. Throughout S3 duration, the auxin content as well as various auxin-related transcripts starts to increase rapidly in the whole fruit (Miller et al. 1987; Trainotti et al. 2007). experiments were carried out in three biological replicates, and error bars represent the SD. The $x$ axis represents the developmental stages indicated by the number of days after bloom (DAB) and by the name of stage. The $y$ axis refers to the mean molecules of PslABP1 per reaction/mean molecules of PsAct

Hence, it appears that $P s l A B P 1$ restores its transcription due to the increase in endogenous auxin content. However, to interpret the differentiation on PslABPl accumulation profile between the fruit pulp and seed, it was necessary to distinguish between the two tissues. Accelerated cell division followed by cell expansion is a signature event of S3 that results in a significant increase in fruit size. Thus, $P s l A B P 1$, as its orthologs in other plant species, should be a 
component of the auxin signal network that controls the cell elongation at low auxin levels (Jones et al. 1998; Christian et al. 2006). The functional inactivation of ABP1 in the model plant cell BY-2 resulted in cell-cycle arrest, which provides evidence that ABP1 is involved in the regulation of cell cycle and division by constituting the first step of auxin-signaling pathway (David et al. 2007). However, in the fully lignified seed (early S3), auxin is needed to complete embryo development. The auxin requirements for the developed embryos as well as PslABP1 transcription decreased along with the progression in embryo maturation (Litz and Gray 1992).

\section{Expression of $P$ slABPl during fruit ripening}

It is almost certain that the chain of modifications that transform a mature green fruit into a ripe fruit occur during S3 (El-Sharkawy et al. 2008, 2009) and involve many different metabolic pathways. Therefore, the factors that control the transition of a fruit from the end of growth to the onset of ripening are of primary importance. In climacteric fruits most aspects of the ripening process are triggered and maintained by ethylene (Lelièvre et al. 1997); however, the factors that initiate ripening/autocatalytic ethylene production have to be triggered independently to ethylene action since ethylene is barely produced during this stage of fruit development (El-Sharkawy et al. 2008). Thus, we decided to investigate the accumulation of $P$ slABPI during ripening to assess a possible autonomous role played by auxin. Two plum cultivars, 'EG' and 'SH', were selected according to their maturity times, early and late, respectively. 'EG' fruit displayed an early, short and rapid ethylene production profile along with high autocatalytic ethylene levels at climacteric peak (Fig. 6a). However, 'SH' fruit exhibited a suppressed climacteric pattern. The fruit ripened slower and later than 'EG' with much lower ethylene levels at climacteric phase, at least six times lesser ethylene levels than 'EG' (Fig. 6b). PslABPI accumulation profile was correlated well with the evolution of climacteric ethylene production in 'EG' mesocarp (Fig. 6a, c) with the exception that the highest transcription signal was detected at pre-climacteric phase, just before the climacteric peak of ethylene production. However, in ' $\mathrm{SH}$ ' pulp, which exhibited a suppressed-climacteric pattern, $P s l A B P 1$ expression profile did not respond to the presence of autocatalytic ethylene during ripening (Fig. 6b, d). Its mRNA was temporally quite constitutive and detected in much lower levels than in 'EG' fruit. Previous study showed that the endogenous auxin content significantly increased in the fruit during ripening, concomitant with the production of climacteric ethylene (Miller et al. 1987; Trainotti et al. 2007). In addition, treatment of fruit with synthetic auxin enhanced both fruit development and ripening (Augustí et al. 1999; Ohmiya 2000; Bregoli et al. 2007). Furthermore, the evaluation of four different ethylene biosynthesis elements (ACC synthesis) and seven ethylene-responsive transcription factors (ERFs) in plum fruits (i.e., the same cultivars studied in the present work) revealed that auxin can affect ethylene production by increasing the transcription of different PsACS and PsERF mRNAs, which play an important role in determining the level of autocatalytic ethylene production and the capacity of the fruit to ripen (El-Sharkawy et al. 2008, 2009). However, the findings that $P S I A B P 1$ maximal accumulation in 'EG' pulp preceded that of climacteric ethylene peak provide more evidence on the role of auxin in stimulating autocatalytic ethylene production by increasing the transcription levels of various ethylene biosynthesis and signal transduction elements (El-Sharkawy et al. 2008, 2009).

In the seed, $P S I A B P 1$ accumulation profile was similar in both plum cultivars, but in much lower levels in 'SH' seeds. Relatively high PslABP1 mRNA levels were detected in non-climacteric phase, $\sim 78 \mathrm{DAB}$ and $\sim 90 \mathrm{DAB}$, respectively (Fig. 6c, d). As ripening progressed, PslABPI transcripts declined gradually to reach a minimal level in post-climacteric stage, $\sim 83$ and $\sim 105 \mathrm{DAB}$, respectively. The role of seed in stone fruit development was determined by Miller et al. (1987) who provided evidence that seed stimulate fruit growth and ripening by providing auxin.

Auxin stimulates ethylene biosynthesis and PslABP1 transcription in late plum fruit

The previous results suggested that the suppressed climacteric phenotype in 'SH' fruits could partially be due to inadequate quantities of auxin to co-ordinate ripening. To test this hypothesis, 'SH' fruits were treated with different concentrations of IAA and $50 \mu \mathrm{M}$ of the auxin inhibitor, TIBA. Untreated 'SH' fruit were used as a control. TIBAtreated fruits were unable to ripen autonomously and their ethylene production remained low even after 35 days post treatment. Untreated, control fruits displayed a climacteric peak after 10 days, with a corresponding ethylene production at the peak of $6.6 \mathrm{nmol} \mathrm{g} \mathrm{g}^{-1} \mathrm{~h}^{-1}$ (Fig. 7a). Fruits treated with 1,10 , and $100 \mu \mathrm{M}$ of IAA, exhibited a climacteric peak after 8,5 , and $3 \mathrm{~d}$ post treatment, respectively; with a corresponding ethylene production at the peak of $16.2,23.6$, and $31.6 \mathrm{nmol} \mathrm{g}{ }^{-1} \mathrm{~h}^{-1}$, respectively (Fig. 7a). 'SH' fruits treated with $10 \mu \mathrm{M}$ of IAA and $50 \mu \mathrm{M}$ TIBA were selected to study the accumulation pattern of PslABPI. TIBA treatment completely inhibited PslABP1 transcription in the fruit (data not shown). However, auxin treatment triggered a dramatic increase in the accumulation profile of PslABPl, suggesting a possible role for auxin (Fig. 7b). 
Fig. 6 Ethylene evolution and steady-state $P$ slABP1 transcript levels assessed by QRT-PCR during early 'EG' (left panel; a and c) and late 'SH' (right panel; b and d) plum fruit ripening. The expression was quantified in pulp (black bars) and in seeds (grey bars). Other details are as described in Fig. 5
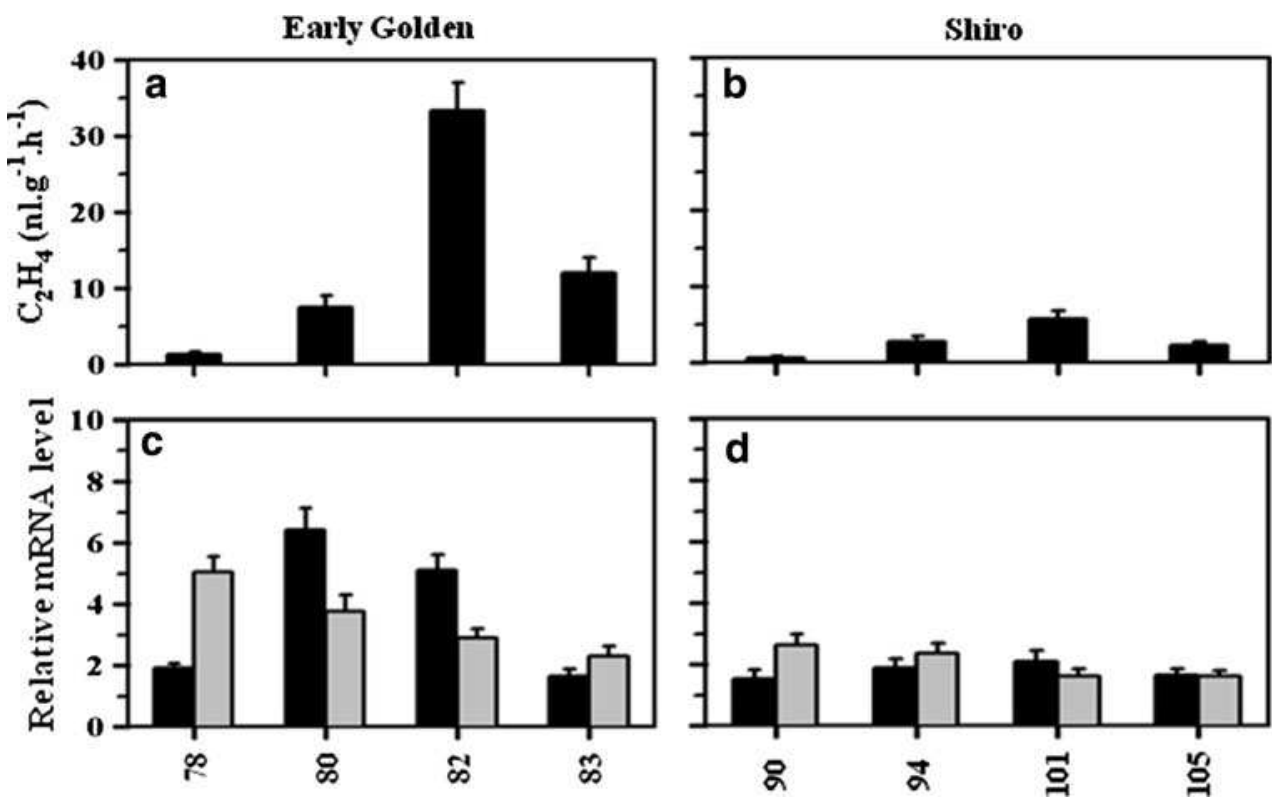
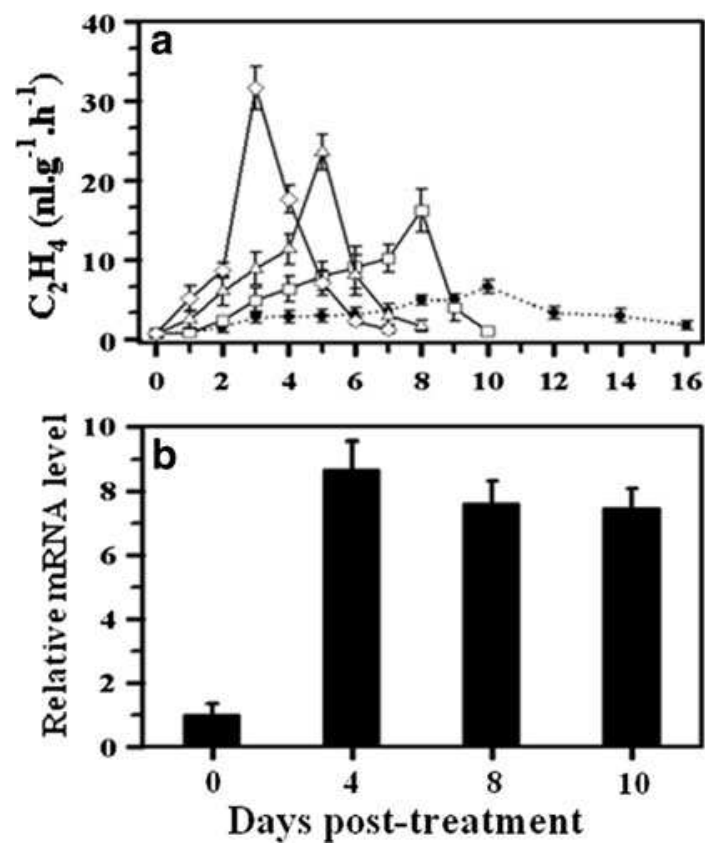

Fig. 7 a Ethylene production of 'SH' plum fruit treated with auxinIAA (filled circles) $0 \mu \mathrm{M}$ (open squares) $1 \mu \mathrm{M}$ (open triangles) $10 \mu \mathrm{M}$, and (open diamonds) $100 \mu \mathrm{M}$. Fruit treated with $0 \mu \mathrm{M}$ auxin served as the control. b The steady-state mRNA levels for PslABP1 in 'SH' fruit during ripening after treatment with $10 \mu \mathrm{M}$ IAA. The $x$ axis in each figure represents days after auxin treatment. Other details are as described in Fig. 5

Based on the correlation between PslABPI mRNA accumulation and the phenotypical ripening stages among the two plum cultivars, apparently the differences in the ripening pattern of both plum cultivars could be partially due to the variation in auxin contents as well as ethylene production. Such variations can influence the capacity of the fruit to produce and respond to ethylene, which results in the differentiation in ripening behavior thereafter (Bregoli et al. 2007; Trainotti et al. 2007; El-Sharkawy et al. 2008, 2009). Thus, theoretically it seems that the scarcity of auxin in the late cultivar can consequently affect the levels of autocatalytic ethylene available for the fruit to initiate ripening. Treatment of late 'SH' fruit with auxin considerably accelerated auxin-induced ethylene production and sensitivity. The fruits restored the typical climacteric pattern to a comparable level with those of early 'EG' fruits. Moreover, our results indicate that the concentration of auxin correlated positively with the precocity of the climacteric phase and the rate of ethylene production at the peak. Therefore, auxin seems to be accumulated rapidly and in higher levels in the early cultivar, which leads to the up-regulation of different transcripts associated with auxin, including auxin and ethylene elements (Trainotti et al. 2007; El-Sharkawy et al. 2008, 2009). Such high accumulation of ripeningrelated proteins (auxin- and ethylene-related proteins) results in the early transition of the mature green fruit into the ripening stage. Once the fruit initiates autocatalytic ethylene, the ripening process will be enhanced in both auxin- and ethylene-dependent manners. Therefore, the possibility of regulating many ethylene-related genes by auxin is the best alternative that explains the significant accumulation of such transcripts during ripening in an ethylene-independent manner (El-Sharkawy et al. 2008, 2009; Ziliotto et al. 2008). However, the accumulation profile of PSlABPl in response to auxin and auxin inhibitor application suggests that its transcript is putatively accumulated in the fruit during ripening in an auxindependent manner. 


\section{References}

Altschul SF, Madden TL, Schaffer AA, Zhang J, Zhang Z, Miller W, Lipman DJ (1997) Gapped BLAST and PSI-BLAST: a new generation of protein database search programs. Nucleic Acids Res 25:3389-3402

Anai T, Miyata M, Kosemura S, Yamamura S, Tsuge T, Matsui M, Uchida H, Hasegawa K (1997) Comparison of abp1 primary sequences from monocotyledonous and dicotyledonous species. J Plant Physiol 151:446-449

Augustí M, Almela V, Andreu I, Juan M, Zacarias L (1999) Synthetic auxin 3,5,6-TPA promotes fruit development and climacteric in Prunus persica L. Batsch. J Hort Sci Biotech 74:556-560

Bauly JM, Sealy IM, Macdonald H, Brearley J, Droge S, Hilmer S, Robinson DG, Venis MA, Blatt MR, Lazarus CM, Napier RM (2000) Overexpression of ABP1 heightens the sensitivity of guard cells to auxin. Plant Physiol 124:1229-1238

Biale JB, Young RE (1981) Respiration and ripening in fruitsretrospect and prospect. In: Journal Friend, Rhodes MJC (eds) Recent advances in the biochemistry of fruits and vegetables. Academic Press, London, pp 1-39

Bregoli AM, Fabbroni C, Costa F, Raimondi V, Costa G (2007) Auxin and ethylene interaction during fruit growth and ripening of Actinidia deliciosa. In: Ramina A, Chang C, Giovannoni J, Klee H, Perata P, Woltering E (eds) Advances in plant ethylene research: proceedings of the 7th international symposium on the plant hormone ethylene. Springer, Berlin, pp $105-107$

Chen JG, Shimomura S, Sitbon F, Sandberg G, Jones AM (2001) The role of auxin-binding protein 1 in the expansion of tobacco leaf cells. Plant J 28:607-617

Chen JG, Ullah H, Young JC, Sussman MR, Jones AM (2011) ABP1 is required for organized cell elongation and division in Arabidopsis embryogenesis. Genes Dev 15:902-911

Christian M, Steffens B, Schenck D, Burmester S, Böttger M, Lüthen $\mathrm{H}$ (2006) How does auxin enhance cell elongation? Roles of auxin-binding proteins and potassium channels in growth control. Plant Biol 8:346-352

David KM, Carnero-Diaz E, Leblanc N, Monestiez M, Grosclaude J, Perrot-Rechenmann C (2001) Conformational dynamics underlie the activity of the auxin-binding protein, Nt-abp1. J Biol Chem 276:34517-34523

David KM, Couch D, Braun N, Brown S, Grosclaude J, PerrotRechenmann C (2007) The auxin-binding protein 1 is essential for the control of cell cycle. Plant J 50:197-206

Davies PJ (2004) Plant hormones: biosynthesis, signal transduction, action. Kluwer, Dordrecht

Dharmasiri N, Dharmasiri S, Estelle M (2005) The F-box protein TIR1 is an auxin receptor. Nature 435:441-445

Dunwell JM, Khuri S, Gane PJ (2000) Microbial relatives of the seed storage proteins of higher plants: conservation of structure and diversification of function during evolution of the cupin superfamily. Microbiol Mol Biol Rev 64:153-179

El-Sharkawy I, Kim WS, El-Kereamy A, Jayasankar S, Svircev AM, Brown DCW (2007) Isolation and characterization of four ethylene signal transduction elements in plums (Prunus salicina L.). J Exp Bot 58:3631-3643

El-Sharkawy I, Kim WS, Jayasankar S, Svircev AM, Brown DCW (2008) Differential regulation of four members of ACC synthase gene family in plum. J Exp Bot 59:2009-2027

El-Sharkawy I, Sherif S, Mila I, Bouzayen M, Jayasankar S (2009) Molecular characterization of seven genes encoding ethyleneresponsive transcriptional factors during plum fruit development and ripening. J Exp Bot 60:907-922
El-Sharkawy I, Mila I, Bouzayen M, Jayasankar S (2010) Regulation of two germin-like protein genes during plum fruit development. J Exp Bot 61:1761-1770

El-Sharkawy I, El Kayal W, Prasath D, Fernández H, Bouzayen M, Svircev AM, Jayasankar S (2012) Identification and genetic characterization of a gibberellin 2-oxidase gene that controls the tree stature and reproductive growth in plum. J Exp Bot 63:1225-1239

Feckler C, Muster G, Feser W, Römer A, Palme K (2001) Mass spectrometric analysis reveals a cysteine bridge between residues 2 and 61 of the auxin-binding protein 1 from Zea mays L. FEBS Lett 509:446-450

Friml J (2003) Auxin transport-shaping the plant. Curr Opin Plant Biol 6:7-12

Giovannoni JJ (2004) Genetic regulation of fruit development and ripening. Plant Cell 16:S170-S180

Hertel R, Thomson K, Russo VEA (1972) In vitro auxin binding to particulate cell fractions from corn coleoptiles. Planta 107:325-340

Hou ZX, Huang WD (2005) Immunohistochemical localization of IAA and ABP1 in strawberry shoot apexes during floral induction. Planta 222:678-687

Jones AM (1994) Auxin-binding proteins. Annu Rev Plant Physiol Plant Mol Biol 45:393-420

Jones AM, Herman EM (1993) KDEL-containing auxin-binding protein is secreted to the plasma membrane and cell wall. Plant Physiol 101:595-606

Jones AM, Im KH, Savka MA, Wu MJ, DeWitt NG, Shillito R, Binns AN (1998) Auxin-dependent cell expansion mediated by overexpressed auxin-binding protein 1 . Science 282:1114-1117

Kepinski S, Leyser O (2005) The Arabidopsis F-box protein TIR1 is an auxin receptor. Nature 435:446-451

Kim YS, Kim D, Jung J (2000) Two isoforms of soluble auxin receptor in rice (Oryza sativa L.) plants: binding property for auxin and interaction with plasma membrane $\mathrm{H}^{+}$-TPase. Plant Growth Regul 32:143-150

Kukuruzinska MA, Lennon K (1998) Protein $N$-glycosylation: molecular genetics and functional significance. Crit Rev Oral Biol Med 9:415-448

Lang A (1961) Auxins in flowering. Encycl Plant Physiol 14:909-950

Lazarus CM, MacDonald H (1996) Characterization of a strawberry gene for auxin-binding protein, and its expression in insect cells. Plant Mol Biol 31:267-277

Leblanc N, Roux C, Pradier JM, Perrot-Rechenmann C (1997) Characterization of two cDNAs encoding auxin-binding proteins in Nicotiana tabacum. Plant Mol Biol 33:679-689

Leblanc N, David K, Grosclaude J, Pradier JM, Barbier-Brygoo H, Labiau S, Perrot-Rechenmann C (1999) A novel immunological approach establishes that the auxin-binding protein, $\mathrm{Nt}$-abp1, is an element involved in auxin signaling at the plasma membrane. J Biol Chem 274:28314-28320

Lelièvre JM, Latché A, Jones B, Bouzayen M, Pech JC (1997) Ethylene and fruit ripening. Physiol Plant 101:727-739

Litz RE, Gray DJ (1992) Organogenesis and somatic embryogenesis. In: Hammerschlag FA, Litz RE (eds) Biotechnology of perennial fruit crops. Academic Press, London, pp 3-34

Löbler M, Klämbt D (1985) Auxin-binding protein from coleoptile membranes of corn (Zea mays L.): purification by immunological methods and characterization. J Biol Chem 260:9848-9853

Lüthen H, Claussen M, Böttger M (1999) Growth: progress in auxin research. Prog Bot 60:315-340

Meisel L, Fonseca B, González S, Baezayates R, Cambiazo V, Campos R, Gonzalez M, Orellana A, Retamales J, Silva H (2005) A rapid and efficient method for purifying high quality total RNA from peaches (Prunus persica) for functional genomics analyses. Biol Res 38:83-88 
Miller AN, Walsh CS, Cohen JD (1987) Measurement of Indole-3Acetic Acid in peach fruits (Prunus persica L. Batsch cv Redhaven) during development. Plant Physiol 84:491-494

Napier RM (1997) Trafficking of the auxin-binding protein. Trends Plant Sci 2:251-255

Napier RM (2001) Models of auxin binding. J Plant Growth Regul 20:244-254

Napier RM, Venis MA (1995) Tansley review No 79: auxin action and auxin-binding proteins. New Phytol 129:167-201

Napier RM, David KM, Perrot-Rechenmann C (2002) A short history of auxin-binding proteins. Plant Mol Biol 49:339-348

Nielsen H, Engelbrecht J, Brunak S, Heijne GV (1997) Identification of prokaryotic and eukaryotic signal peptides and prediction of their cleavage sites. Protein Eng 10:1-6

Ohmiya A (2000) Effects of auxin on growth and ripening of mesocarp discs of peach fruit. Sci Hort 84:309-319

Ohmiya A, Motoyuki K, Sakai S, Hayashi T (1993) Purification and properties of an auxin-binding protein from the shoot apex of peach tree. Plant Cell Physiol 34:177-183

Quint M, Gray WM (2006) Auxin signaling. Curr Opin Plant Biol 9:448-453

Scherer FEG (2011) AUXIN-BINDING-PROTEIN1, the second auxin receptor: what is the significance of a two-receptor concept in plant signal transduction? J Exp Bot 62:33393357

Shimomura S, Watanabe S, Ichikawa H (1999) Characterization of auxin-binding protein 1 from tobacco: content, localization and auxin-binding activity. Planta 209:118-125
Teale WD, Paponov IA, Palme K (2006) Auxin in action: signalling, transport and the control of plant growth and development. Nat Rev Mol Cell Biol 7:847-859

Thomas C, Meyer D, Wolff M, Himber C, Alioua M, Steinmetz A (2003) Molecular characterization and spatial expression of the sunflower $A B P 1$ gene. Plant Mol Biol 52:1025-1036

Thornton JM (1981) Disulphide bridges in globular proteins. J Mol Biol 151:261-287

Trainotti L, Tadiello A, Casadoro G (2007) The involvement of auxin in the ripening of climacteric fruits comes of age: the hormone plays a role of its own and has an intense interplay with ethylene in ripening peaches. $\mathrm{J}$ Exp Bot 58:3299-3308

Tromas A, Braun N, Muller P, Khodus T, Paponov IA, Palme K, Ljung K, Lee JY, Benfey P, Murray JAH, Scheres B, PerrotRechenmann C (2009) The auxin binding protein 1 is required for differential auxin responses mediating root growth. PLoS One 4:e6648. doi:10.1371/journal.pone.0006648

Varki A (1993) Biological roles of oligosaccharides: all of the theories are correct. Glycobiol 3:97-130

Woo EJ, Marshall J, Bauly J, Chen JG, Venis M, Napier RM, Pickersgill RW (2002) Crystal structure of auxin-binding protein 1 in complex with auxin. EMBO J 21:2877-2885

Yin K, Han X, Xu Z, Xue H (2009) Arabidopsis GLP4 is localized to the Golgi and binds auxin in vitro. Acta Biochim Biophys Sin (Shanghai) 6:478-487

Ziliotto F, Begheldo M, Rasori A, Bonghi C, Tonutti B (2008) Transcriptome profiling of ripening nectarine (Prunus persica $\mathrm{L}$. Batsch) fruit treated with 1-MCP. J Exp Bot 59:2781-2791 